\title{
The Relation between Displacive Disorder, Premartensitic Instabilities and the Martensitic Transformation in $\beta-\mathrm{Cu}-\mathrm{Zn}$ Alloys
}

\author{
By L. Delaey, J. Van Paemel, M. Chandrasekaran and R. Cottam \\ Departement Metaalkunde, Katholieke Universiteit Leuven, B-3030 Heverlee, Belgium
}

(Received 29 April 1974)

\begin{abstract}
Recent literature [Delaey, L., Perkins, A. J. \& Massalki, T. B. (1972). J. Mater. Sci. 7, 1197; Delaey, L., Van Paemel, J. \& Struyve, T. (1972). Scripta Metall. 6, 507; Takezawa, K. \& Sato, S. (1973). J. Jap. Inst. Metals, 37, 793; Cornelis, I., Oshima, R., Tong, H. C. \& Wayman, C. M. (1974). Scripta Metall. 8, 133; Perkins, J. (1974). Scripta Metall. 8, 31] shows that a relation may exist between the premartensitic instabilities and the displacive disorder observed in the parent b.c.c. phase. In this work the apparent relationship is further discussed. Further evidence will be given by means of electron diffraction patterns of the occurrence of the displacive modes in a $\mathrm{Cu}-47$ at. $\% \mathrm{Zn} \beta$-phase alloy. The displacive modes are: (1) a transverse wave with a $\frac{1}{2}\langle 110\rangle$ wave vector and the $\langle 1 \overline{1} 0\rangle$ polarization vector; (2) a longitudinal wave with a $\frac{2}{3}\langle 111\rangle$ wave vector and a polarization vector $\langle 11 \overline{1}\rangle$ and (3) a transverse wave with $\frac{1}{3}\langle 112\rangle$ wave vector and the $\langle 11 \overline{1}\rangle$ polarization vector. The influence of the high density of vacancies on the occurrence of these modes will be discussed together with the influence of changes in point defect densities referring to further transformation (massive, bainitic, martensitic). A simple crystallographic approach in obtaining the final martensitic structure $[3 R, 1 R, 2 H)$ from the initial displacive modes is presented.
\end{abstract}

J. Appl. Cryst. (1975). 8, 141

A Study on the Fine Structure in Metastable $\beta_{1}$ Crystal of $\mathrm{Cu}-\mathbf{4 0}$ wt. $\% \mathrm{Zn}$ Alloy

By K. Takezawa and S. Sato

Department of Applied Physics, Faculty of Engineering, Hokkaido University, Sapporo 060, Japan

(Received 29 April 1974)

Previous investigations have revealed that the metastable $\beta_{1}$ crystal of $\mathrm{Cu}-40 \mathrm{wt} . \% \mathrm{Zn}$ alloy, retained from the high-temperature range by quenching, was easily transformed martensitically [Sato, S. \& Takezawa, K. (1968). Proc. Int. Conf. on the Strength of Metals and Alloys, Suppl. to Trans. AIME, J. Inst. Metals, 9, 925-929] or bainitically [Takezawa, K. \& Sato, S. (1972). Kinzoku Gakkaishi (J. Japan Inst. Met. in Japanese), 35, 469-475] to the long-period close-packed crystal. In the course of the above investigations, very fine contrast was of ten observed in the transmission electron microscopic image of untransformed $\beta_{1}$ regions. The contrast was thought to be produced by the fine transformation product in the matrix. But no further study on this structure was performed at that time. In the present work, a detailed analysis of the various diffraction patterns containing additional spots has been made in order to determine the crystal structure of the fine product in the matrix. The obtained structure is orthorhombic with $A=(2 a / 3) .[1 \overline{1} 2]_{\beta}, B=\left(a / 2[\overline{111}]_{\beta}\right.$ and $C=a[110]_{\beta}$, which is also considered as a distorted h.c.p. structure. The relation between the product and the martensite or the bainite was examined by respectively cooling or heating the quenched specimen in an electron microscope. The (110) [110] shears play an important role in producing the product. The products may be thought as the embryos of close-packed structure, which are transformed by a mechanism similar to that of Burgers for the martensitic transformation from b.c.c. to h.c.p. 